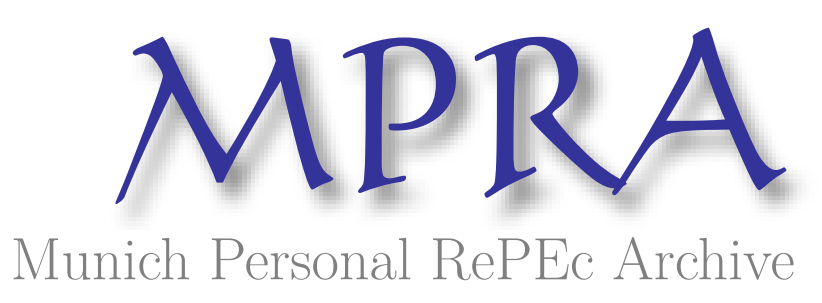

\title{
The Employment Cycles of Neighboring Cities
}

\author{
Wall, Howard J. \\ Murus Research
}

7 March 2011

Online at https://mpra.ub.uni-muenchen.de/29410/

MPRA Paper No. 29410, posted 10 Mar 2011 12:21 UTC 


\title{
The Employment Cycles of Neighboring Cities
}

\author{
Howard J. Wall \\ Murus Research
}

March 7, 2011

\begin{abstract}
This paper examines the spatial interaction of neighboring cities over their employment cycles. The cycles of neighboring cities tend to be more similar to one another than are those of non-neighboring cities, although this is due primarily to neighbors' tendency to be in the same state. In addition to these same-state effects, neighborness interacts with industry and human capital in ways that make the cyclical interaction of neighbors different from that of non-neighbors. Specifically, neighboring cities with similar levels of educational attainment and establishment size tend to have more-similar employment cycles, but neighboring cities with similar racial compositions tend to have less-similar employment cycles.
\end{abstract}

JEL Codes: R10, E32

Keywords: Neighboring cities, employment cycles

*E-mail: wall@MurusResearch.com 


\section{Introduction}

Just as the national business cycle is often characterized as a sequence of expansion and recession phases, local-level employment growth can be described as a sequence of switches between periods of expansion and contraction — an employment cycle. As demonstrated by Owyang, Piger, and Wall (2005, 2010), state and city employment cycles can differ substantially from the national cycle, and national recessions have tended to spread in recession-specific geographic patterns. ${ }^{1}$ City-level cycles also differ from one another: During 1990-2008, the employment cycles of a typical pair of large U.S. cities were in the same phase 71 percent of the time, and cities in the same state or region tended to have more-similar cycles. Strikingly, however, similar industrial mixes did not translate into similar employment cycles (Owyang, Piger, and Wall, 2010).

This paper focuses on the employment cycles of neighboring cities-i.e., large contiguous cities within the same metro area. The economies of neighboring cities are relatively integrated, so one might expect them to have similar employment cycles. Even if macroeconomic shocks directly affect neighboring cities differently, the cities' interrelatedness might mean that each city's shock propagates spatially to affect each other. Countervailing this notion, however, are models of urban systems, which allow the possibility that neighboring cities have divergent employment cycles. For example,

\footnotetext{
${ }^{1}$ The effects of the 1990-91 recession, for example, began much earlier on the coasts before spreading inward and receding to the regions from which it sprang. The effects of the 2001 recession, however, were felt earliest in the middle of the country before spreading to the coasts and, eventually, receding to the middle.
} 
in the evolutionary hierarchy models of Fujita and Mori (1997) and Fujita, Krugman, and Mori (1999), neighboring cities arise out of a single evolutionary process through which one agglomeration center becomes two, each serving a different set of functions within the metro-area economy. If cities with similar functions have similar cycles, and there is a consistent division of functions across metro areas, then cities in the same position on their metro areas hierarchy will have similar cycles.

This paper is a contribution to the urban systems literature in that its purpose is to determine the links, if any, between the employment cycles of neighboring cities. Because of its methodology and attention to relatively high-frequency data, the paper follows directly from the literature applying the tools of empirical macroeconomics to geographically disaggregated data. ${ }^{2}$ To a large extent, this macro/urban/regional literature exists as separate from the rest of urban/regional economics in that it has tended to look at the myriad high-frequency time-series differences across geographic entities within the U.S. rather than addressing traditional urban questions: The word “agglomeration" appears only rarely. ${ }^{3}$ The present paper departs from these roots by focusing on the spatial and agglomerative links between cities, offering a new perspective on the organization of cities and the links between them.

\footnotetext{
${ }^{2}$ Notable papers in this literature include, but are not limited to, Carlino and Mills (1993); Carlino and DeFina (1995, 1998, 1999, 2004); Clark (1998); Carlino and Sill (2001); Del Negro (2002); Partridge and Rickman (2002, 2005); Owyang, Piger, and Wall (2008); Owyang, Rapach, and Wall (2009); and Hamilton and Owyang (forthcoming).

${ }^{3}$ This literature does, however, share the general outlook of the urban system literature which sees the overall economy as a grouping of interrelated subnational economies (Abdel-Rahman and Anas, 2005).
} 
For my analysis, I take at face value the statistical criteria for metro divisions within a metropolitan statistical area. ${ }^{4}$ Metro divisions fit the notion of neighboring cities very well in that they are distinct but related cities, each large enough to have its own agglomerative process. ${ }^{5}$ My data set is quarterly payroll employment for 25 metro divisions within 10 of the 11 MSAs that have metro divisions as components. I excluded the four metro divisions of the Boston-Cambridge-Quincy MSA, three of which are relatively small, because the Markov-switching model has a difficult time separating employment growth into expansion and contraction phases for small cities. Consistent data and definitions are available for the 25 metro divisions (henceforth, cities) back to 1990.Q1 and my data ends with 2009.Q1, currently the most recent quarter not subject to rebenchmarking.

I find that, on average, the employment cycles of neighboring cities are more similar than are those of the average city pair, but that this effect of neighborness disappears once I control for the fact that neighboring cities tend to be the same state and region. Controlling for these and other factors, I find no evidence that neighboring cities have similar employment cycles solely because of their neighborness. On the other hand, neighborness interacts with industry and human capital in ways that make the cyclical

\footnotetext{
${ }^{4}$ According to the General Accounting Office (GAO-04-758), the combination of two or more adjacent metro division occurs when the employment interchange measure is at least 25 . This measure is the sum of the percentages of residents the metro divisions who work in the other metro division. For employment interchange between 15 and 25, local opinion can be used to determine that two metro divisions are in the same MSA. Dobkins and Ioannides (2001), for example, found the growth rates of neighboring cities to be interdependent.

${ }^{5}$ Note that the these distinctions are devised largely from county-level data and that more-granular data will yield more subcenters (McMillen and Smith, 2003). See also Berliant and Wang (2008).
} 
interaction of neighbors different from non-neighbors. For neighbors, employment cycles are related to similarities in mean establishment size, racial composition, and educational attainment. Also, in a result that harkens back to Christaller's (1933) central place theory and modern models of urban hierarchy, the employment cycles of the largest cities across metro areas tend to be similar to one another. In other words, a city's place in the urban hierarchy will play a role in determining how macroeconomic shocks affect its employment cycle.

\section{City Employment Cycles}

To determine each city's pattern of expansion and contraction, I apply the Markov-switching model of Hamilton (1989) to city-level employment data. The estimation procedure is a straightforward application of Kim and Nelson (1999), the details of which are outlined in Owyang, Piger, and Wall (2005). In this model, an employment cycle is assumed to have two phases — expansion and contraction — which the city economy switches between infrequently. Each phase has its own structure and, therefore, its own growth rate. ${ }^{6}$ Deviations from the two growth rates are treated as noise. Put simply, the model compares a city's actual employment growth rate to its two phase growth rates and determines the probability that the city's employment is in contraction. Persistence matters in that the probability of being in contraction depends on the previous period's growth rate. The model performs well for large cities, i.e., the

\footnotetext{
${ }^{6}$ Owyang, Piger, Wall, and Wheeler (2008) find that expansion growth rates are related to some of the usual variables used in growth regressions, but that these variables are not related to contraction growth rates.
} 
probability of contraction is usually close to either one or zero (Owyang, Piger, and Wall, 2010). By convention, a period is determined to be contractionary if the estimated probability of contraction exceeds 0.5 .

The cities' employment cycles are summarized by Table 1, which lists the cities in order of their MSA and Metro Division identification numbers. Note that, because the estimation uses growth rates, 1990:1 is excluded. Quarters for which the cities are in contraction are denoted with a " $\mathbf{m}$ " and expansionary quarters are blank, and periods of national employment contraction are indicated by a shaded background. As should be clear from the table, there is a strong tendency for any city to be in contraction around the same time as the country as a whole, indicating the occurrence of common macroeconomic events. Nonetheless, a city's cycle can differ a great deal from that of other cities and the country as a whole: (i) Some cities did not experience employment contraction at all during periods of national contractions; (ii) City-level contractions need not be in synch with each other; and (iii) Cities can experience idiosyncratic contractions when nearly all other cities are in expansion.

As shown elsewhere for a larger set of cities, there is a broad geographic pattern to the occurrence of city employment contractions (Owyang, Piger, and Wall, 2010). My present focus, however, is on the narrow patterns between neighboring cities. Specifically, an examination of Table 1 reveals that there can be substantial differences in the employment cycles of neighboring cities, although some neighbors are closely related. For example, Dallas-Plano-Irving and Fort Worth-Arlington are very much in 
synch; whereas Washington-Arlington-Alexandria and Bethesda-Frederick-Gaithersburg have relatively little in common; and Chicago-Naperville-Joliet, Gary, and Lake CountyKenosha hardly look like cities within the same metro area.

To measure the extent to which two city employment cycles are in synch, I use their concordance, that is, the percentage of time the two cycles are in the same phasee (Harding and Pagan, 2002). More precisely, the concordance between the employment cycles of cities $i$ and $j$ is

$$
C_{i j}=\frac{100}{T} \sum_{t=1}^{T}\left[\left(S_{i t}-S_{j t}\right)+\left(1-S_{i t}\right)\left(1-S_{j t}\right)\right],
$$

where $S_{i t}$ and $S_{j t}$ equal 1 when city $i$ or $j$ is in contraction, and zero otherwise. $T$ is the number of time periods. Applying this to the occurrence of employment contractions summarized by Table 1 yields measures of concordance for each of the 300 city pairs. The remainder of the paper examines these concordances, with particular focus on the concordances between cities within the same metro area.

\section{Conceptual Framework}

The mean concordance across all 300 city pairs is 74.4 , meaning that, on average, two cities were in the same phase of the employment cycle 74.4 percent of the time. Pairs of contiguous cities in the same metro area tended to be in synch more often than this, 81.7 percent of the time, so, arithmetically, the employment cycles of neighboring cities were more closely related than average. Finding the effect of neighborness is not as simple as calculating this number, however, because doing so ignores that each city plays 
simultaneous roles in its own metro area and in the broader system of urban areas. In such a system, each city is linked in some way to each of the other cities (its city effect is the average of these) and to its neighbor by virtue of overlapping agglomeration (neighborness). These two roles need to be separated from one another in the event that the city effects are correlated with neighborness.

The potential importance of city-specific effects is illustrated in Table 2, which provides cities' mean concordances within their own metro area and with all other cities. By comparing the two columns one can see a strong tendency for cities to be more in synch with their neighbors than with the entire set of cities. Still, six cities-ChicagoNaperville-Joliet, Detroit-Livonia-Dearborn, Warren-Farmington Hills-Troy, MiamiMiami-Beach-Kendall, Washington-Arlington-Alexandria, and Bethesda-FrederickGaithersburg — were more in synch with their non-neighbors than with their neighbors. Note also the large difference in the cities' mean concordances with other cities overall: Five had mean concordances lower than 70 and four had mean concordances higher than 80.

Further confounding a clear estimate of neighborness is that neighboring cities tend to be in the same state, although not always. Indeed, as reported in Table 3, the mean concordance of city pairs whose principal cities lie in the same state is higher than that for cities in the same metro area, 83.5 versus 73.9. It's beyond the present scope, but an obvious possibility is that differences in state-level policies affect the timing and the length of employment cycles, thereby accounting for at least some of the above-average 
intra-metro concordance. Such policies might include corporate and personal income tax rates, unemployment insurance benefits, sales taxes, banking regulation, minimum wage, etc. Further, some city pairs have a secondary state link in that one city's outer counties are in the same state as the principal city and/or outlying counties of the other. Because the mean concordance for these city pairs is also above average (79.3), there is some evidence that this secondary link might matter .

To differing degrees, every metro area has one main city at the top of the local hierarchy and serves as something like a central place. The fact that neighbors tend to develop into such a hierarchy suggests a separation of roles and functions within a metro area. The largest city, for example, might include headquarters and offices while the smaller city contains space-intensive activities such as production and transport. ${ }^{7}$ If the different functions, even within the same industry, are affected differently by macroeconomic shocks, then cities in the same tier of the urban hierarchy might tend to have similar employment cycles. There is certainly evidence of this as the average concordance between the largest cities in each metro area is 80.7 .

When separating the determinants of concordance, keep in mind that each metro areas in the sample was formed through its own combination of geography and chance, so their component cities will have their own positions in the metro area's hierarchy. ${ }^{8}$ The evolution of the Los Angeles-Long Beach-Santa Ana MSA, for example, can be

\footnotetext{
${ }^{7}$ See Rossi-Hansberg, Sarte, and Owens (2009) for a theoretical treatment along these lines.

${ }^{8}$ See Dobkins and Ioannides (2001) for a detailed look at the development of neighboring cities in the United States.
} 
thought of as having followed something like the evolutionary process of Fujita and Mori (1997) and Fujita, Krugman, and Mori (1999): Santa Ana-Anaheim-Irvine began life as the hinterlands of what is now Los Angeles-Long Beach-Glendale before developing its own agglomeration center and status as a large city. The development of Dallas-Fort Worth-Arlington, on the other hand, bears little resemblance to such a process. It became a metro area as the existing cities of Dallas and Forth Worth grew toward one another, eventually becoming a more-unified system that could be categorized as a metro area.

As reported in Table 4, measures of agglomeration differ more between neighbors than between non-neighbors, indicating that there is something distinct about the development of neighbors relative to each other. Specifically, the average difference in the number of establishments between non-neighbors was 65.5 thousand, whereas the average difference between neighbors was 95.2 thousand, about 45 percent larger.

Further, the average difference in the number of establishments per square mile was 30.4 for non-neighbors and 41.0 for neighbors, 35 percent higher.

Finally, as reported in Table 4, between-neighbor differences in industrial mix and human capital are smaller than the differences between non-neighbors. The average sum of the absolute differences in industry shares of employment is 19.8 for neighbors, but 25.4 for non-neighbors. Clark (1998), for one, demonstrates how employment fluctuations can be decomposed into national, subnational, and industry shocks, with each playing a significant role. Although our fluctuations are at a much lower frequency than those considered by Clark, it's not unreasonable to believe that industrial similarity is 
related to employment cycle similarity. This was not found by Owyang, Piger, and Wall (2010), but they did not focus on the role that industrial similarity might play between neighboring cities. Similarly, human capital similarity might play a special role for neighbors: The sum of absolute difference in race shares is 21.7 for neighbors and 26.1 for non-neighbors, and neighbors have more-similar levels of educational attainment. On average, the difference in shares of the population aged 25 and older with at least a high school diploma was 4 percentage points for neighbors and 4.7 percentage points for nonneighbors. ${ }^{9}$

\section{Geography, Agglomeration, and Hierarchy}

This section estimates of the effect of neighborness on employment cycle concordance by controlling for measures of geography, agglomeration, and urban hierarchy. To control for city, state, and regional effects, I estimate two versions of the following regression equation:

$$
\ln C_{i j}=\alpha+\alpha_{i}+\alpha_{j}+\beta N_{i j}+\gamma^{\prime} \mathbf{X}_{\mathrm{ij}}+\varepsilon_{i j}
$$

where $\alpha_{i}$ and $\alpha_{j}$ are city dummies and $N_{i j}$ equals 1 if $i$ and $j$ are contiguous and in the same metro area, and $\mathbf{X}_{\mathbf{i j}}$ is a vector of dummies indicating whether $i$ and $j$ have their principal cities in the same state, have outlying counties in the same state as the principal city or outlying counties of the other, or have principal cities in the same Census division. The coefficient on $N_{i j}$ is the direct effect of neighborness.

\footnotetext{
${ }^{9}$ Hoynes (2000) and Engemann and Wall (2010) show how the effects of recessions are deeper for blacks and those with less than a high school degree.
} 
Results for the two versions of this model are provided in Table 5. The first version, Model A, allows for city-specific effects but assumes that there are no state and regional effects (i.e., it imposes the restriction that $\gamma$ is a zero vector). This estimation yields a statistically significant effect for being neighbors: Controlling for the cityspecific differences in concordance, being neighbors tends to add 7.7 points to a citypair's concordance [i.e., $100 \times\left(\mathrm{e}^{\beta}-1\right)=7.7$ ], which is same as the arithmetic difference. This result, however, does not account for the possibility of state and regional effects. To do so, I remove the restriction on $\gamma$ to obtain Model B and find that the higher-thanaverage mean concordance between neighbors is due to the tendency for their principal cities to be in the same state, not to their being neighbors. Specifically, the effect of being neighbors is statistically no different from zero, whereas having principal cities in the same state tends to add 13.3 points to the concordance between cities. As is clear from the log likelihoods for the two models, the restriction that $\gamma$ is a zero vector is easily rejected. ${ }^{10}$

As established above, it is not necessarily neighborness that accounts for the higher average concordance between neighboring cities, but perhaps the cities' tendencies to lie principally in the same state. The next step is to control for the potential roles of agglomeration and hierarchy, which I do by estimating

$$
\ln C_{i j}=\alpha+\alpha_{i}+\alpha_{j}+\beta N_{i j}+\gamma^{\prime} \mathbf{X}_{\mathrm{ij}}+\omega L_{i j}+\lambda^{\prime} \mathbf{A}_{\mathrm{ij}}+\boldsymbol{\theta}^{\prime}\left(N_{i j} \mathbf{A}_{\mathrm{ij}}\right)+\varepsilon_{i j}
$$

\footnotetext{
${ }^{10}$ The results of likelihood tests comparing all estimates in the paper are in an appendix.
} 
where $\mathbf{A}_{\mathbf{i j}}$ is a vector of variables measuring the extent to which $i$ and $j$ are similarly agglomerated and $L_{i j}$ is a dummy that equals 1 if $i$ and $j$ are both the largest cities in their respective metro area. To differentiate the importance of agglomeration for neighbors from that of non-neighbors, the agglomeration vector is also interacted with the $N_{i j}$ dummy. Similarity in agglomeration is measured by $\log \left(1-\left|a_{i}-a_{j}\right| / a_{i} a_{j}\right)$, where $a_{i}$ are the $a_{j}$ are the sizes (number of establishments) or densities (establishments per square mile) of $i$ and $j{ }^{11}$

Table 6 provides the estimation results for three versions of (3): Model C imposes the restriction that agglomeration is unrelated to concordance $(\lambda=\theta=0)$, Model D imposes the restriction that hierarchy is unrelated to concordance $(\omega=0)$, and Model E is unrestricted. It is clear from the log likelihoods that the restrictions to obtain Models C and $\mathrm{D}$ are easily rejected, so Model $\mathrm{E}$ is preferred statistically. In any event, the results from the two restricted models differ little from the unrestricted one, so the agglomeration variables are not strongly correlated with the hierarchy dummy.

According to Model E, the effect of neighborness is statistically no different from zero and there is a large effect for cities being in the same state, just as when agglomeration and hierarchy were not considered. More interestingly, the coefficient on $L_{i j}$ is positive and statistically significant: when two cities are both the largest city in their metro area: their concordance tends to be 7.7 points higher than otherwise. Further,

\footnotetext{
${ }^{11}$ The number of establishments is the average over 2000-2005 and is from the Census Bureau's State and Metropolitan Area Data Book as of February 4, 2009. Area is from the same source and is land area per square mile.
} 
agglomeration also matters: In general, the more similar the two cities are in density, the more similar their employment cycles are, although size similarity is not significant. On the other hand, the is no separate statistically significant link between concordance and agglomeration for neighbors.

\section{Industry and Human Capital}

The final set of estimates controls for industry mix and human capital, which have been shown elsewhere to be important determinants of fluctuations at the subnational level. If recessions and recoveries affect types of industries or people the same way, then cities that are similar in these regards might have similar employment cycles. To test for this I include four variables, three of which are indices that convert the sum of the absolute differences in the relevant shares into a measure of similarity. For example, to measure similarity in industry mix, I use $I_{i j}=\log \left(1-\sum_{\mathrm{k}}\left|x_{i k}-x_{j k}\right|\right)$, where $x_{i k}$ and $x_{j k}$ are the shares of total employment in industry $k .^{12}$ To control for human capital similarities, I use a racial similarity index that makes use of population racial shares, and an educational similarity index that uses the share of the population aged 25 and older with at least a high school diploma. ${ }^{13}$ To control for similarities in the sizes of employers, I include $E_{i j}=\log \left(1-\left|e_{i}-e_{j}\right| / e_{i} e_{j}\right)$, where $e_{i}$ and $e_{j}$ are the mean establishment sizes in $i$ and $j$. Each of these four variables are included on their own and in interaction with the neighbor dummy. Specifically, I estimate

\footnotetext{
${ }^{12}$ These shares are averaged over the sample period.

${ }^{13}$ Race and education data are for 2006 from the State and Metropolitan Area Data Book.
} 


$$
\begin{aligned}
\ln C_{i j}= & \alpha+\alpha_{i}+\alpha_{j}+\beta N_{i j}+\gamma^{\prime} \mathbf{X}_{\mathrm{ij}}+\omega L_{i j}+\lambda^{\prime} \mathbf{A}_{\mathrm{ij}}+\boldsymbol{\theta}^{\prime}\left(N_{i j} \mathbf{A}_{\mathrm{ij}}\right) \\
& +\rho \boldsymbol{I}_{i j}+\tau I_{i j} M S A_{i j}+\boldsymbol{\kappa}^{\prime} \mathbf{H}_{\mathrm{ij}}+\boldsymbol{\delta}^{\prime}\left(N_{i j} \mathbf{H}_{\mathrm{ij}}\right)+\varepsilon_{i j},
\end{aligned}
$$

where $\mathbf{H}_{\mathbf{i j}}$ is a vector of the two human capital similarity indices.

The estimation results for three versions of (4) are presented in Table 7: Model F allows industrial similarity to matter but restricts the effects of human capital to zero $(\kappa=$ $\delta=0)$, Model G restricts the effects of industrial similarity to zero $(\rho=\tau=0)$ but allows human capital to matter, and Model $\mathrm{H}$ imposes no restrictions. Notice that, although some of the new variables are statistically significant, likelihood ratio tests cannot reject the null that these specifications are statistically no different from Model E. This means that the estimates of the coefficients on everything other than the industry and human capital variables are statistically the same across Models E-H. Even so, the adjusted $R^{2}$ values suggest that the addition of these variables does provide additional explanatory power relative to Model E. Finally, according to likelihood ratio tests, Models F and G are not statistically different from Model $\mathrm{H}$ and these three specifications are very similar in terms of goodness of fit.

As just noted, Model $\mathrm{H}$ provides the same results as Model E for the effects of geographic designations, agglomeration, and hierarchy. For the industry variables introduced in (4), note that concordance is unrelated to industrial mix, regardless of whether the cities are neighbors or not. On the other hand, mean establishment size is related to concordance, but only for neighbors - neighboring cities with similarly sized firms tend to have similar employment cycles. From the results for Model F it is clear that the qualitative results for the industry variables would be obtained whether or not the 
human capital variables are included. On the other hand, the magnitude of the coefficient on mean establishment size for neighbors does change when human capital variables are included, a point I return to below.

Of the human capital variables included in Model $\mathrm{H}$, only the two that are interacted with the neighbor dummy are statistically significant. Specifically, the more similar their levels of high school attainment, the more similar are neighbors' employment cycles. But, the more similar their racial mix, the less similar their employment cycles. It is striking that human capital similarity is important only for neighboring cities and do not reflect of a general effect between any two cities. Because of this, the results cannot be reflections of how racial and educational categories affected over the cycle. Instead, it must have something to do with the fact that neighbors' labor markets are somewhat integrated.

Keep in mind that employment data are based on the locations of jobs and that race and education data are based on the locations of potential employees. In principle, any resident in one city is a potential employee in either neighboring city, as long as they are willing to bear the commuting costs. If we think of educational similarity as a measure of the employment substitutability of residents of one city for residents of the other, then neighboring cities that have similar levels of educational attainment will have more-integrated labor markets. Therefore, neighbors' employment cycles will be more similar to one another the more similar the cities' educational attainment. 
The negative relationship between concordance and racial similarity might be counterintuitive at first glance, but it is consistent with spatial/racial mismatch. For whatever reason, there is a tendency for cities to be divided internally by race and, on a larger scale, for the largest city in a metro area to have a higher concentration of minority groups. ${ }^{14}$ Potential employers, however, are spread more evenly across two neighboring cities. ${ }^{15}$ The greater the spatial/racial mismatch between cities, the more likely it is that members of every racial group will commute between their city of residence and their city of employment. Therefore, the less similar two neighbors are in their racial composition, the more commuting there will be between the cities, and the more integrated will be their labor markets.

As is seen from a comparison of Models $\mathrm{G}$ and $\mathrm{H}$, the inclusion of the industry variables is important in obtaining these results. In Model G, racial mix is statistically insignificant and the coefficient on high school attainment is much larger. Statistically, the reason that the results from Model $\mathrm{H}$ differ from those from Models $\mathrm{F}$ and $\mathrm{G}$ is that there is a strong correlation for differences in mean establishment size and race for neighbors, but not for non-neighbors: For neighbors, the correlation between racial similarity index and establishment size similarity is 0.727 , whereas it is 0.137 for nonneighbors. Because of this correlation, the link between racial similarity and

\footnotetext{
${ }^{14}$ Martin (2004) and Hellerstein, Neumark, and McInerney (2008) provide recent estimates of the extent of spatial/racial mismatch.

${ }^{15}$ This is, admittedly, a very partial-equilibrium explanation and takes the location of employers and residents as given. Because the present concern is with relatively high-frequency events, however, mobility is most likely a secondary concern. See Arnott (1998) for a general equilibrium treatment of spatial mismatch.
} 
concordance for neighbors is not obtained unless mean establishment size is controlled for. Explanations for why this correlation exists, and why it is for neighbors alone, are lacking in the existing literature. However, the fact that it holds only for neighbors suggests that it has something to do with the interrelated formation and evolution of neighboring cities.

\section{Concluding Remarks}

On average, the employment cycles of neighboring cities are more similar to one another than are the cycles of non-neighboring cities. However, this is not due to their neighborness directly, but to the tendency for neighboring cities to be in the same state. Neighborness does, however, interact with industry and human capital in ways that make the cyclical interaction of neighbors different from that of non-neighbors. According to my most general specification, Model $\mathrm{H}$, similarities in neighbors' employment cycles are related to similarities in mean establishment size, racial composition, and educational attainment.

To put the results from Model $\mathrm{H}$ into perspective, Table 8 provides the estimated coefficients in terms of concordance points. The coefficients for the three statistically significant dummy variables were converted as above, whereas the effect for the other significant variables are measured as one standard deviation increases in the relevant similarity index. As noted above, geographic designation is important and the effect of being in the same state is relatively large: All else equal, the concordance of two nonneighbors in the same state tends to be 12.2 points higher than it is for non-neighbors in 
different states. The urban hierarchy matters in that the concordance of two cities at the top of their metro area's hierarchy tend to be 6.3 points higher than otherwise. Finally, agglomeration is important too: The concordance for a city pair that is one-standard deviation more similar than average will tend to be 3.6 points higher, all else equal.

Neighborness is related to concordance only through its interaction with the characteristics of employers and employees in the neighboring cities. Concordance tends to be 7 points higher for neighbors whose similarity in mean establishment size is onestandard deviation above average, all else equal. For racial and educational similarity, the effects are -5.1 points and 3.5 points, respectively. The negative link between concordance and racial similarity is consistent with spatial/racial mismatch. The positive link between concordance and similarity in educational attainment is consistent with the idea that educational similarity indicates the extent to which the residents of the two cities are substitutes for each other. 
Appendix: Likelihood Ratios

\begin{tabular}{|c|c|c|c|c|c|c|c|c|c|c|c|c|}
\hline & $\mathbf{A}$ & & B & & C & & D & & $\mathbf{E}$ & $\mathbf{F}$ & & $\mathbf{G}$ \\
\hline B & $321.15^{*}$ & & & & & & & & & & & \\
\hline C & $428.95^{*}$ & 1 & $7.80^{*}$ & & & & & & & & & \\
\hline D & $730.85^{*}$ & 4 & $9.70 *$ & & n-nested & & & & & & & \\
\hline $\mathbf{E}$ & $837.93 *$ & 5 & $16.78^{*}$ & 4 & $8.98 \dagger$ & 1 & $7.08^{*}$ & & & & & \\
\hline $\mathbf{F}$ & $1242.04 *$ & 9 & $20.89 *$ & 8 & $13.09 *$ & 5 & $11.19^{*}$ & 4 & 4.11 & & & \\
\hline G & $1243.47 *$ & 9 & $22.32 *$ & 8 & $14.52 *$ & 5 & $12.62 *$ & 4 & 5.54 & non-nested & & \\
\hline H & $1645.55^{*}$ & 13 & $24.39 *$ & 12 & $16.60 *$ & 9 & $14.70 *$ & 8 & 7.62 & 43.51 & 4 & 2.08 \\
\hline
\end{tabular}

The number in italics is the number of restrictions imposed to obtain the nested model. $\mathrm{A} *$ or $\dagger$ indicates statistical significance at the 5 percent and 10 percent levels, respectively. 


\section{References}

Abdel-Rahman, H.M and A. Anas (2005). Theories of Systems of Cities. In Henderson, V. and J.F. Thisse (Eds.), Handbook of Regional and Urban Economics, 4. Amsterdam: Elsevier, 2293-2340.

Arnott, R. (1998). Economic Theory and the Spatial Mismatch Hypothesis. Urban Studies 35(7), 1171-1185.

Berliant, M. and P. Wang (2008). Urban Growth and Subcenter Formation: A Trolley Ride from the Staples Center to Disneyland and the Rose Bowl. Journal of Urban Economics 63, 679-693.

Carlino. G.A. and L. Mills (1993). Are U.S. Regional Incomes Converging? A Time Series Analysis. Journal of Monetary Economics 32, 335-346.

Carlino, G.A. and R.H. DeFina (1995). Regional Income Dynamics. Journal of Urban Economics 37, 88-106.

Carlino, G.A. and R.H. DeFina (1998). The Differential Regional Effects of Monetary Policy. Review of Economics and Statistics 80, 572-587.

Carlino, G.A. and R.H. DeFina (2004). How Strong is Co-Movement in Employment Over the Business Cycle? Evidence from State/Sector Data. Journal of Urban Economics 55, 298-315.

Carlino, G. and K. Sill (2001). Regional Income Fluctuations: Common Trends and Common Cycles. Review of Economics and Statistics 83, 446-456.

Christaller, W. (1933). Central Places in Southern Germany, In translation (1966), translated by Baskin, C.W. Prentice-Hall, Englewood Cliffs, New Jersey.

Clark, T. (1998). Employment Fluctuations in U.S. Regions and Industries: The Roles of National, Region-Specific, and Industry-Specific Shocks. Journal of Labor Economics, 202-229

Del Negro, M. (2002). Asymmetric Shocks Among U.S. States. Journal of International Economics 56, 273-297

Dobkins, L.H. and Y.M Ioannides (2001). Spatial Interactions among U.S. Cities: 19001990. Regional Science and Urban Economics 31(6), 701-731.

Engemann, K.M. and H.J. Wall (2010). The Effects of Recessions Across Demographic Groups. Federal Reserve Bank of St. Louis Review 92(1), 1-26.

Fujita, M., P. Krugman, and T. Mori (1999). On the Evolution of Hierarchical Urban Systems. European Economic Review 43, 209-251.

Fujita M. and T. Mori (1997). Structural Stability and the Evolution of Urban Systems. Regional Science and Urban Economics 27, 399-442.

Hamilton, J.D. (1989). A New Approach to the Economic Analysis of Nonstationary Time Series and the Business Cycle. Econometrica 57, 357-384.

Hamilton, J.D. and M.T. Owyang (forthcoming). The Propagation of Regional Recessions. Review of Economics and Statistics. 
Harding, D. and A. Pagan (2002). Dissecting the Cycle: A Methodological Investigation. Journal of Monetary Economics 49, 365-381.

Hellerstein, J.K., D. Neumark, and M. McInerney (2008). Spatial Mismatch or Racial Mismatch? Journal of Urban Economics 64, 464-479.

Hoynes, H. (2000). The Employment and Earnings of Less Skilled Workers Over the Business Cycle. In D.E. Card and R.M. Blank (Eds.), Finding Jobs: Work and Welfare Reform. New York: Russell Sage Foundation, 23-71.

Kim, C.J. and C. Nelson (1999). State-Space Models with Regime Switching: Classical and Gibbs-Sampling Approaches with Applications. Cambridge, MA: MIT Press.

Martin, R.W. (2004). Can Black Workers Escape Spatial Mismatch? Employment Shifts, Population Shifts, and Black Unemployment in American Cities. Journal of Urban Economics 55, 179-194.

McMillen, D.P. and S.C. Smith (2003). Then Number of Subcenters in Large Urban Areas. Journal of Urban Economics 5, 321-338.

Owyang, M.T., J. Piger, and H.J. Wall (2005). Business Cycle Phases in U.S. States. Review of Economics and Statistics 87, 604-616.

Owyang, M.T., J. Piger, and H.J. Wall (2010). Discordant City Employment Cycles. Federal Reserve Bank of St. Louis Working Paper 2010-019A.

Owyang, M.T., J. Piger, and H.J. Wall (2008). A State-Level Analysis of the Great Moderation. Regional Science and Urban Economics 38(6), 578-579.

Owyang, M.T., J. Piger, H.J. Wall, and C.H. Wheeler (2008). The Economic Performance of Cities: A Markov-Switching Approach. Journal of Urban Economics 64(3), 538-550.

Owyang, M.T., D. Rapach, and H.J. Wall (2009). States and the Business Cycle. Journal of Urban Economics 65(2), 181-194.

Partridge, M.D and D.S. Rickman (2002). Did the New Economy Vanquish the Regional Business Cycle? Contemporary Economic Policy 20(4), 456-469.

Partridge, M.D and D.S. Rickman (2005). Regional Cyclical Asymmetries in an Optimal Currency Area: An Analysis Using US State Data. Oxford Economic Papers 57(3), 373-397.

Rossi-Hansberg E, P.-D. Sarte, and R.. Owens III (2009). Firm Fragmentation and Urban Patterns. International Economic Review 50(1), 143-186. 
Table 1. City-Level Employment Cycles

\begin{tabular}{|c|c|c|c|c|c|c|c|c|c|c|c|c|c|c|c|c|c|c|c|}
\hline & 1990 & 1991 & 1992 & 1993 & 1994 & 1995 & 1996 & 1997 & 1998 & 1999 & 2000 & 2001 & 2002 & 2003 & 2004 & 2005 & 2006 & 2007 & 2008 \\
\hline & & & & & & & & & & & & & & & & & & & \\
\hline Chicago-Naperville-Joliet & & & & & & & & & & & & & & & & & & & \\
\hline Gary & & & & & & & & & & & & & & & & & & & \\
\hline Lake County-Kenosha & & & & & & & & & & & & & & & & & & & \\
\hline Dallas-Plano-Irving & & & & & & & & & & & & & & & & & & & \\
\hline Fort Worth-Arlington & & & & & & & & & & & & & & & & & & & \\
\hline Detroit-Livonia-Dearborn & & & & & & & & & & & & & & & & & & & \\
\hline Warren-Farmington Hills-Troy & & & & & & & & & 口 & & & & & & & & & & \\
\hline Los Angeles-Long Beach-Glendale & & & & & & & & & & & & & & & & & & & \\
\hline Santa Ana-Anaheim-Irvine & & & & & & & & & & & & & & & & & & & \\
\hline Ft. Lauderdale-Pomp. Bch-Deerfie & & & & & & & & & & & & & & & & & & & \\
\hline Miami-Miami Beach-Kendall & & & & & & & & & & & & & & & & & & & \\
\hline W. Palm Bch-Boca Raton-Boynto & & & & & & & & & & & & & & & & & & & \\
\hline Edison & & & & & & & & & & & & & & & & & & & \\
\hline Nassau-Suffolk & & & & & & & & & & & & & & & & & & & \\
\hline Newark-Union & & & & & & & & & & & & & & & & & & & \\
\hline New York-Wayne-White Plains & & & & & & & & & & & & & & & & & & & \\
\hline Camden & & & & & & & & & & & & & & & & & & & \\
\hline Philadelphia & & & & & & & & & & & & & & & & & & & \\
\hline Wilmington & & & & & & & & & & & & & & & & & & & \\
\hline Oakland-Fremont-Hay ward & & & & & & & & & & & & & & & & & & & \\
\hline San Francisco-San Mateo-Redwoo & & & & & & & & & & & & & & & & & & & \\
\hline Seattle-Bellevue-Everett & & & & & & & & & & & & & & & & & & & \\
\hline Tacoma & & & & & & & & & & & & & & & & & & & \\
\hline Washington-Arlington-Alexandria & & & & & & & & & & & & & & & & & & & \\
\hline Bethesda-Frederick-Gaithersburg & & & & & & & & & & & & & & & & & & & \\
\hline
\end{tabular}

A indicates a quarter in which the city was in an employment contraction. The shaded areas are the periods during which national employment was in contraction (Owyang, Piger, and Wall, 2010). 
Table 2. Mean Concordances

\begin{tabular}{|c|c|c|c|}
\hline MSA & Metro Division (City) & $\begin{array}{c}\text { With } \\
\text { Neighbor(s) } \\
\end{array}$ & $\begin{array}{c}\text { With All } \\
\text { Cities } \\
\end{array}$ \\
\hline \multirow{3}{*}{$\begin{array}{l}\text { Chicago-Naperville- } \\
\text { Joliet, Il-IN-WI }\end{array}$} & Chicago-Naperville-Joliet, IL & 74.3 & 80.4 \\
\hline & Gary, IN & 78.9 & 71.1 \\
\hline & Lake County-Kenosha, Il-WI & 69.7 & 63.0 \\
\hline \multirow{2}{*}{$\begin{array}{l}\text { Dallas-Fort Worth- } \\
\text { Arlington, TX }\end{array}$} & Dallas-Plano-Irving, TX & \multirow{2}{*}{93.4} & 80.1 \\
\hline & Fort Worth-Arlington, TX & & 78.5 \\
\hline \multirow{2}{*}{$\begin{array}{l}\text { Detroit-Warren- } \\
\text { Livonia, MI }\end{array}$} & Detroit-Livonia-Dearborn, MI & \multirow{2}{*}{59.2} & 62.7 \\
\hline & Warren-Farmington Hills-Troy, MI & & 67.5 \\
\hline \multirow{2}{*}{$\begin{array}{l}\text { Los Angeles-Long } \\
\text { Beach-Santa Ana, CA }\end{array}$} & Los Angeles-Long Beach-Glendale, CA & \multirow{2}{*}{88.2} & 77.5 \\
\hline & Santa Ana-Anaheim-Irvine, CA & & 74.3 \\
\hline \multirow{3}{*}{$\begin{array}{l}\text { Miami-Ft. Lauderdale- } \\
\text { Pompano Beach, FL }\end{array}$} & Ft. Lauderdale-Pompano Beach-Deerfield Beach, FL & 89.5 & 76.0 \\
\hline & Miami-Miami Beach-Kendall, FL & 82.9 & 81.3 \\
\hline & West Palm Beach-Boca Raton-Boynton Beach, FL & 96.1 & 74.8 \\
\hline \multirow{4}{*}{$\begin{array}{l}\text { New York-Northern } \\
\text { New Jersey-Long } \\
\text { Island, NY-NJ-PA }\end{array}$} & Edison, $\mathrm{NJ}$ & 88.2 & 76.6 \\
\hline & Nassau-Suffolk, NY & 86.8 & 79.1 \\
\hline & Newark-Union, NJ-PA & 88.2 & 76.6 \\
\hline & New York-Wayne-White Plains, NY-NJ & 82.9 & 79.9 \\
\hline \multirow{3}{*}{$\begin{array}{l}\text { Philadelphia-Camden- } \\
\text { Wilmington, PA-NJ- } \\
\text { DE-MD }\end{array}$} & Camden, NJ & 82.9 & 77.9 \\
\hline & Philadelphia, PA & 83.6 & 79.7 \\
\hline & Wilmington, DE-MD-NJ & 86.2 & 80.1 \\
\hline \multirow{2}{*}{$\begin{array}{l}\text { San Francisco- } \\
\text { Oakland-Fremont, CA }\end{array}$} & Oakland-Fremont-Hayward, CA & \multirow{2}{*}{76.3} & 60.0 \\
\hline & San Francisco-San Mateo-Redwood City, CA & & 71.3 \\
\hline \multirow{2}{*}{$\begin{array}{l}\text { Seattle-Tacoma- } \\
\text { Bellevue, WA }\end{array}$} & Seattle-Bellevue-Everett, WA & \multirow{2}{*}{84.2} & 72.8 \\
\hline & Tacoma, WA & & 73.0 \\
\hline \multirow{2}{*}{$\begin{array}{l}\text { Washington-Arlington- } \\
\text { Alexandria, DC-VA- } \\
\text { MD-WV }\end{array}$} & Washington-Arlington-Alexandria, MD & \multirow{2}{*}{65.8} & 77.0 \\
\hline & Bethesda-Frederick-Gaithersburg, DC-VA-MD-WV & & 69.5 \\
\hline
\end{tabular}




\section{Table 3. Mean Concordance within}

Geographic Designations

\begin{tabular}{lcc}
\hline All City Pairs & \multicolumn{2}{c}{74.4} \\
& Yes & No \\
\cline { 2 - 3 } Neighbors & 81.7 & 74.0 \\
Same Principal State & 83.5 & 73.9 \\
Same Secondary State & 79.3 & 74.2 \\
Same Census Division & 78.0 & 73.6 \\
\hline
\end{tabular}

Table 4. Cross-City Differences in Measures of Agglomeration, Industry Mix, and Human Capital

\begin{tabular}{|c|c|c|}
\hline & Neighbors & Non-Neighbors \\
\hline Establishments, Thousands & 95.2 & 65.5 \\
\hline Establishments per Square Mile & 41.0 & 30.4 \\
\hline Sum of Differences in Industry Shares & 19.8 & 25.4 \\
\hline Mean Establishment Size & 1.8 & 3.0 \\
\hline Sum of Differences in Race Shares ${ }^{a}$ & 21.7 & 26.1 \\
\hline Difference in Share with HS Diploma & 4.0 & 4.7 \\
\hline
\end{tabular}

${ }^{\mathrm{a}}$ White, Black, Asian, and American Indian or Alaska Native 
Table 5. Concordance and Geographic Similarity

\begin{tabular}{l|cccc}
\hline & \multicolumn{3}{|c}{ Model A } & \multicolumn{2}{c}{ Model B } \\
\cline { 2 - 5 } & Coeff. & s.e. & Coeff. & s.e. \\
\hline Constant & $4.465^{*}$ & 0.021 & $4.477^{*}$ & 0.022 \\
Neighbor & $0.075^{*}$ & 0.027 & -0.011 & 0.024 \\
Principal State & & & $0.124^{*}$ & 0.033 \\
Secondary State & & & -0.025 & 0.024 \\
Census Division & & & 0.036 & 0.022 \\
\hline Gary & $-0.124^{*}$ & 0.021 & $-0.129^{*}$ & 0.020 \\
Lake County-Kenosha & $-0.255^{*}$ & 0.043 & $-0.259^{*}$ & 0.042 \\
\hline Dallas-Plano-Irving & -0.002 & 0.017 & -0.008 & 0.017 \\
Fort Worth-Arlington & -0.024 & 0.019 & -0.029 & 0.019 \\
\hline Detroit-Livonia-Dearborn & $-0.262^{*}$ & 0.046 & $-0.273^{*}$ & 0.047 \\
Warren-Farmington Hills-Troy & $-0.178^{*}$ & 0.028 & $-0.188^{*}$ & 0.027 \\
\hline Los Angeles-Long Beach-Glendale & $-0.036 \dagger$ & 0.021 & $-0.059^{*}$ & 0.019 \\
Santa Ana-Anaheim-Irvine & $-0.078^{*}$ & 0.020 & $-0.101^{*}$ & 0.020 \\
\hline Ft. Lauderdale-Pompano Beach-Deerfield Beach & $-0.065^{*}$ & 0.027 & $-0.079^{*}$ & 0.027 \\
Miami-Miami Beach-Kendall & 0.013 & 0.013 & -0.004 & 0.016 \\
W. Palm Beach-Boca Raton-Boynton Beach & $-0.077^{*}$ & 0.026 & $-0.094^{*}$ & 0.027 \\
\hline Edison & $-0.063^{*}$ & 0.031 & $-0.074^{*}$ & 0.029 \\
Nassau-Suffolk & -0.021 & 0.023 & -0.033 & 0.023 \\
Newark-Union & $-0.061^{*}$ & 0.027 & $-0.071^{*}$ & 0.026 \\
New York-Wayne-White Plains & -0.012 & 0.018 & -0.012 & 0.019 \\
\hline Camden & -0.046 & 0.031 & $-0.057^{*}$ & 0.028 \\
Philadelphia & -0.011 & 0.017 & -0.013 & 0.017 \\
Wilmington & -0.007 & 0.017 & -0.003 & 0.019 \\
\hline Oakland-Fremont-Hayward & $-0.313^{*}$ & 0.050 & $-0.335^{*}$ & 0.051 \\
San Francisco-San Mateo-Redwood City & $-0.124^{*}$ & 0.028 & $-0.146^{*}$ & 0.026 \\
\hline Seattle-Bellevue-Everett & $-0.105^{*}$ & 0.022 & $-0.117^{*}$ & 0.022 \\
Tacoma & $-0.106^{*}$ & 0.027 & $-0.117^{*}$ & 0.028 \\
\hline Washington-Arlington-Alexandria & $-0.055^{\dagger}$ & 0.031 & $-0.059 \dagger$ & 0.030 \\
Bethesda-Frederick-Gaithersburg & $4.465^{*}$ & 0.021 & $4.477^{*}$ & 0.022 \\
\hline Log Likelihood & 223.917 & 234.494 \\
Adjusted R ${ }^{2}$ & 0.530 & & 0.558 \\
\hline City & & 0.487 & & 0.512 \\
\hline
\end{tabular}

City effects are measured relative to the excluded city, Chicago-Naperville-Joliet. A* or $\dagger$ indicates statistical significance at the 5 percent and 10 percent levels, respectively. 
Table 6. Agglomeration and Central Places

\begin{tabular}{|c|c|c|c|c|c|c|}
\hline & \multicolumn{2}{|c|}{ Model C } & \multicolumn{2}{|c|}{ Model D } & \multicolumn{2}{|c|}{ Model E } \\
\hline & Coeff. & s.e. & Coeff. & s.e. & Coeff. & s.e. \\
\hline$\overline{\text { Constant }}$ & $4.428^{*}$ & 0.024 & $4.493 *$ & 0.025 & $4.438^{*}$ & $\overline{0.031}$ \\
\hline Neighbor & 0.002 & 0.023 & -0.015 & 0.044 & -0.003 & 0.042 \\
\hline Principal State & $0.120^{*}$ & 0.031 & $0.105^{*}$ & 0.034 & $0.101 *$ & 0.032 \\
\hline Secondary State & -0.022 & 0.025 & -0.023 & 0.026 & -0.022 & 0.026 \\
\hline Census Division & $0.038 \dagger$ & 0.022 & $0.041 \dagger$ & 0.022 & $0.043 \dagger$ & 0.022 \\
\hline Largest Cities & $0.075^{*}$ & 0.025 & & & $0.073^{*}$ & 0.027 \\
\hline Size & & & -0.000 & 0.623 & -0.414 & 0.672 \\
\hline Neighbor*Size & & & 1.066 & 1.865 & 1.042 & 1.778 \\
\hline Density & & & $1.219 *$ & 0.371 & $1.216^{*}$ & 0.360 \\
\hline Neighbor*Density & & & -0.993 & 1.050 & -0.967 & 0.995 \\
\hline Gary & $-0.099 *$ & 0.023 & -0.038 & 0.032 & -0.023 & 0.031 \\
\hline Lake County-Kenosha & $-0.229 *$ & 0.044 & $-0.259 *$ & 0.042 & $-0.234 *$ & 0.044 \\
\hline Dallas-Plano-Irving & -0.007 & 0.016 & 0.006 & 0.018 & 0.009 & 0.017 \\
\hline Fort Worth-Arlington & 0.001 & 0.021 & 0.010 & 0.022 & $0.041 \dagger$ & 0.025 \\
\hline Detroit-Livonia-Dearborn & $-0.272 *$ & 0.047 & $-0.268 *$ & 0.046 & $-0.266^{*}$ & 0.046 \\
\hline Warren-Farmington Hills-Troy & $-0.158^{*}$ & 0.028 & $-0.186^{*}$ & 0.028 & $-0.154^{*}$ & 0.029 \\
\hline Los Angeles-Long Beach-Glendale & $-0.057^{*}$ & 0.016 & $-0.052 *$ & 0.019 & $-0.051^{*}$ & 0.017 \\
\hline Santa Ana-Anaheim-Irvine & $-0.070 *$ & 0.022 & $-0.086 *$ & 0.021 & $-0.054 *$ & 0.024 \\
\hline Ft. Lauderdale-Pompano Beach-Deerf. Beach & $-0.049 \dagger$ & 0.028 & $-0.077 *$ & 0.028 & -0.046 & 0.030 \\
\hline Miami-Miami Beach-Kendall & -0.003 & 0.014 & -0.004 & 0.017 & -0.001 & 0.016 \\
\hline W. Palm Beach-Boca Raton-Boynton Beach & $-0.064 *$ & 0.027 & $-0.090 *$ & 0.028 & $-0.059^{*}$ & 0.029 \\
\hline Edison & -0.045 & 0.031 & $-0.074 *$ & 0.031 & -0.043 & 0.034 \\
\hline Nassau-Suffolk & -0.003 & 0.024 & -0.023 & 0.025 & 0.008 & 0.027 \\
\hline Newark-Union & -0.041 & 0.028 & $-0.072 *$ & 0.027 & -0.041 & 0.031 \\
\hline New York-Wayne-White Plains & -0.013 & 0.016 & 0.006 & 0.021 & 0.005 & 0.019 \\
\hline Camden & -0.028 & 0.029 & $-0.054 \dagger$ & 0.028 & -0.026 & 0.030 \\
\hline Philadelphia & -0.013 & 0.014 & -0.011 & 0.018 & -0.010 & 0.016 \\
\hline Wilmington & 0.026 & 0.021 & 0.006 & 0.021 & 0.028 & 0.021 \\
\hline Oakland-Fremont-Hayward & $-0.305^{*}$ & 0.052 & $-0.333 *$ & 0.052 & $-0.302^{*}$ & 0.053 \\
\hline San Francisco-San Mateo-Redwood City & $-0.139 *$ & 0.024 & $-0.140 *$ & 0.026 & $-0.130 *$ & 0.024 \\
\hline Seattle-Bellevue-Everett & $-0.113^{*}$ & 0.022 & $-0.109 *$ & 0.022 & $-0.103 *$ & 0.022 \\
\hline Tacoma & $-0.087 *$ & 0.028 & $-0.056 \dagger$ & 0.030 & -0.037 & 0.029 \\
\hline Washington-Arlington-Alexandria & $-0.056 \dagger$ & 0.031 & $-0.058 \dagger$ & 0.031 & $-0.053 \dagger$ & 0.032 \\
\hline Bethesda-Frederick-Gaithersburg & $-0.120 *$ & 0.026 & $-0.150 *$ & 0.025 & $-0.121 *$ & 0.027 \\
\hline Log Likelihood & 238. & & 239. & & 242 & \\
\hline & 0.5 & & 0.5 & & 0.5 & \\
\hline Adjusted $\mathrm{R}^{2}$ & 0.46 & & 0.4 & & 0.4 & \\
\hline
\end{tabular}

City effects are measured relative to the excluded city, Chicago-Naperville-Joliet. A * or $\dagger$ indicates statistical significance at the 5 percent and 10 percent levels, respectively. 
Table 7. Industry Mix and Human Capital

\begin{tabular}{|c|c|c|c|c|c|c|}
\hline & \multicolumn{2}{|c|}{ Model F } & \multicolumn{2}{|c|}{ Model G } & \multicolumn{2}{|c|}{ Model H } \\
\hline & Coeff. & s.e. & Coeff. & s.e. & Coeff. & s.e. \\
\hline Constant & $4.441^{*}$ & 0.035 & $4.458 *$ & 0.034 & $4.459 *$ & 0.037 \\
\hline Neighbor & -0.005 & 0.094 & 0.082 & 0.052 & 0.020 & 0.085 \\
\hline Principal State & $0.113^{*}$ & 0.033 & $0.108^{*}$ & 0.033 & $0.114^{*}$ & 0.035 \\
\hline Secondary State & -0.028 & 0.027 & -0.019 & 0.026 & -0.033 & 0.028 \\
\hline Census Division & $0.045^{*}$ & 0.022 & $0.045 \dagger$ & 0.023 & $0.048 *$ & 0.023 \\
\hline Largest Cities & $0.070^{*}$ & 0.027 & $0.063^{*}$ & 0.027 & $0.061 *$ & 0.028 \\
\hline Size & -0.421 & 0.673 & -0.436 & 0.680 & -0.438 & 0.679 \\
\hline Neighbor*Size & -0.386 & 1.771 & 2.257 & 1.779 & -1.081 & 2.273 \\
\hline Density & $1.192 *$ & 0.369 & $1.244 *$ & 0.362 & $1.255^{*}$ & 0.368 \\
\hline Neighbor*Density & 0.832 & 1.142 & -1.060 & 1.028 & 1.440 & 1.397 \\
\hline Industrial Mix & -0.022 & 0.080 & & & -0.028 & 0.083 \\
\hline Neighbor*Industrial Mix & -0.322 & 0.461 & & & -0.253 & 0.393 \\
\hline Mean Establishment Size & 0.345 & 1.059 & & & 0.559 & 1.027 \\
\hline Neighbor*Mean Establishment Size & $9.243^{*}$ & 3.832 & & & $12.91 *$ & 5.526 \\
\hline Racial Mix & & & 0.007 & 0.063 & 0.001 & 0.065 \\
\hline Neighbor*Racial Mix & & & 0.021 & 0.075 & $-0.195 \dagger$ & 0.117 \\
\hline Share with a HS Diploma & & & 0.285 & 0.198 & 0.300 & 0.202 \\
\hline Neighbor*Share with a HS Diploma & & & $1.597 *$ & 0.553 & $1.043 *$ & 0.521 \\
\hline Gary & -0.030 & 0.031 & -0.028 & 0.031 & -0.032 & 0.031 \\
\hline Lake County-Kenosha & $-0.238^{*}$ & 0.046 & $-0.239 *$ & 0.043 & $-0.245^{*}$ & 0.045 \\
\hline Dallas-Plano-Irving & 0.006 & 0.018 & 0.012 & 0.019 & 0.014 & 0.019 \\
\hline Fort Worth-Arlington & 0.035 & 0.025 & 0.037 & 0.026 & 0.036 & 0.026 \\
\hline Detroit-Livonia-Dearborn & $-0.259 *$ & 0.047 & $-0.258^{*}$ & 0.057 & $-0.257 *$ & 0.059 \\
\hline Warren-Farmington Hills-Troy & $-0.154 *$ & 0.032 & $-0.154 *$ & 0.030 & $-0.160 *$ & 0.032 \\
\hline Los Angeles-Long Beach-Glendale & $-0.057^{*}$ & 0.018 & -0.029 & 0.022 & -0.032 & 0.023 \\
\hline Santa Ana-Anaheim-Irvine & $-0.062 *$ & 0.026 & $-0.055^{*}$ & 0.027 & $-0.062 *$ & 0.028 \\
\hline Ft. Lauderdale-Pompano Beach-Deerf. Beach & -0.043 & 0.033 & $-0.052 \dagger$ & 0.030 & -0.044 & 0.033 \\
\hline Miami-Miami Beach-Kendall & 0.000 & 0.018 & 0.021 & 0.021 & 0.024 & 0.023 \\
\hline W. Palm Beach-Boca Raton-Boynton Beach & $-0.058 \dagger$ & 0.034 & $-0.070 *$ & 0.030 & $-0.063 \dagger$ & 0.034 \\
\hline Edison & -0.046 & 0.034 & -0.048 & 0.034 & -0.051 & 0.033 \\
\hline Nassau-Suffolk & 0.012 & 0.028 & 0.007 & 0.028 & 0.013 & 0.028 \\
\hline Newark-Union & -0.044 & 0.031 & -0.050 & 0.031 & -0.051 & 0.031 \\
\hline New York-Wayne-White Plains & 0.002 & 0.021 & 0.016 & 0.020 & 0.011 & 0.022 \\
\hline Camden & -0.034 & 0.031 & -0.039 & 0.031 & -0.042 & 0.032 \\
\hline Philadelphia & -0.013 & 0.017 & -0.017 & 0.017 & -0.017 & 0.018 \\
\hline Wilmington & 0.021 & 0.022 & 0.016 & 0.022 & 0.015 & 0.023 \\
\hline Oakland-Fremont-Hayward & $-0.310^{*}$ & 0.055 & $-0.312 *$ & 0.057 & $-0.318^{*}$ & 0.059 \\
\hline San Francisco-San Mateo-Redwood City & $-0.139 *$ & 0.026 & $-0.136 *$ & 0.032 & $-0.144 *$ & 0.033 \\
\hline Seattle-Bellevue-Everett & $-0.107 *$ & 0.024 & $-0.098 *$ & 0.024 & $-0.100^{*}$ & 0.025 \\
\hline Tacoma & -0.045 & 0.031 & -0.041 & 0.029 & -0.045 & 0.031 \\
\hline Washington-Arlington-Alexandria & -0.057 & 0.040 & -0.054 & 0.036 & -0.059 & 0.043 \\
\hline Bethesda-Frederick-Gaithersburg & $-0.125^{*}$ & 0.030 & $-0.121 *$ & 0.029 & $-0.124 *$ & 0.032 \\
\hline Log Likelihood & 244. & & 245. & & 246 & \\
\hline & 0.5 & & 0.5 & & & \\
\hline Adjusted $\mathrm{R}^{2}$ & 0.5 & & 0.5 & & 0.5 & \\
\hline
\end{tabular}

City effects are measured relative to the excluded city, Chicago-Naperville-Joliet. A * or $\uparrow$ indicates statistical significance at the 5 percent and 10 percent levels, respectively. 
Table 8. Summary of Effects on Concordance, Model H

\begin{tabular}{l|c}
\hline & Concordance Points \\
\hline Cities in the Same Principal State & 12.1 \\
Cities in the Same Census Division & 4.9 \\
Cities are Both the Largest in Their Metro Areas & 6.3 \\
Similarity in Density Between Any Cities ${ }^{\mathrm{a}}$ & 3.6 \\
Similarity in Mean Establishment Size Between Neighbors & \\
Racial Similarity Between Neighbors & \\
& \\
Educational Similarity Between Neighbors & \\
& \\
\hline $\begin{array}{l}\text { The table includes only those variables that are statistically significant. } \\
\text { difference between the mean and one standard deviation above the mean. }\end{array}$
\end{tabular}

